\title{
Tetralogy of Fallot: in good shape?
}

\author{
Barbara J. M. Mulder · Ernst E. van der Wall
}

Published online: 16 December 2008

(C) The Author(s) 2008. This article is published with open access at Springerlink.com

Tetralogy of Fallot (TOF) is the most common cause of cyanotic congenital heart disease and is associated with a high prevalence of pulmonary regurgitation following repair often requiring later pulmonary valve replacement (PVR) [1-13]. Adults with repaired TOF and significant chronic pulmonary regurgitation are at risk for progressive right ventricular (RV) dilatation and dysfunction [14-23]. Helbing et al. [1] showed that impaired relaxation and restriction to filling affected RV function in patients with repair of TOF and pulmonary regurgitation. Uebing et al. [2] demonstrated that RV endsystolic volume is a useful measure for estimating RV function after TOF repair depicting parameters of

Editorial comment to the paper entitled "Correlation of right ventricular ejection fraction and tricuspid annular plane systolic excursion in tetralogy of fallot by magnetic resonance imaging" by Sheehan. Doi: 10.1007/s10554-008-9387-0.

B. J. M. Mulder

Department of Cardiology, B2-240, Academic Medical Center, Meibergdreef 9, 1105 AZ Amsterdam,

The Netherlands

E. E. van der Wall ( $\square)$

Department of Cardiology, Leiden University Medical

Center, Rijnsburgerweg 2, P.O. Box 9600, Leiden,

The Netherlands

e-mail: e.e.van_der_wall@lumc.nl systolic and diastolic RV function. Assessment of RV function is important in the management of these patients in particular when it comes to optimal timing of surgery for PVR. Timing of surgery must be carefully considered, weighing the up-front risks of surgery and possible repeat surgery against the risk of ongoing pulmonary regurgitation [24, 25]. Therefore, monitoring RV volume and function is useful for managing patients with TOF.

Detailed and precise evaluation of RV function by cardiac imaging has been a long-standing challenge in clinical medicine. Two-dimensional (2D) imaging has been used to this purpose, but the complex shape of the RV has precluded accurate estimation of RV volume by $2 \mathrm{D}$ echocardiography using geometric models. Accordingly, all 2D echocardiographic methods show a rather poor performance in comparison with cardiovascular magnetic resonance imaging (CMR) [26]. Consequently, three-dimensional (3D) imaging methods combined with analysis using the multiple slice technique are more accurate because reliance on geometric modeling is eliminated. Over the past years, a vast experience had been built with CMR to investigate LV and RV dynamics [27-41]. As such, CMR has become the gold standard for quantitative analysis of RV anatomy, function, and shape [42-47].

Kayser et al. [48] evaluated the effect of throughplane motion on tricuspid flow measurements performed with CMR velocity mapping in nine normal subjects and 15 patients with RV disease. Eight 
parameters of RV diastolic function were derived from the tricuspid flow measurements, both before and after a correction for through-plane motion. Measurements of E-peak, A-peak, and time-to-peak filling rate changed significantly after correction for through-plane motion. Tricuspid flow as a marker of $\mathrm{RV}$ diastolic function should be corrected for the effect of through-plane motion to improve functional evaluation of the RV.

Greenberg et al. [49] recently identified E- and Awave flow patterns across the tricuspid valve in TOF patients. Results from CMR phase contrast velocityencoded flow quantification correlated well with measurements of right ventricular enlargement. The authors studied 33 children following TOF repair who had CMR examinations that included cine imaging to quantify ventricular size and function and flow analysis across the atria-ventricular valves to evaluate ventricle in-flow patterns. A reduction in the E:A wave ratio across the tricuspid valve was associated with RV diastolic dysfunction and correlated well with RV enlargement. As a result, reduction in the E:A wave ratio across the tricuspid valve was considered a new useful criterion for determining the timing of valved pulmonary conduit surgery in children following TOF repair.

Over the past years, evaluation of RV shape has been proposed using tricuspid annular plane systolic excursion (TAPSE). Previous 2D echocardiographic studies have shown that a TAPSE value of less than $18 \mathrm{~mm}$ was associated with increased RV systolic dysfunction [50], whereby a TAPSE of less than $15 \mathrm{~mm}$ was associated with an adverse prognosis [51]. TAPSE has been shown to correlate highly with RV ejection fraction in normal subjects and patients with ischemic heart disease [52]. However, correlations between TAPSE and RVEF using CMR have not previously been studied in patients with repaired TOF.

In the current issue of the International Journal of Cardiovascular Imaging, Morcos et al. [53] evaluated whether TAPSE measurements by CMR correlated with RVEF in surgically repaired TOF patients. TAPSE was measured from systolic displacement of the RV-free wall/tricuspid annular plane junction in the apical 4-chamber view in 7 normal subjects and 14 TOF patients. All TOF patients had signs of tricuspid regurgitation. Because the authors had previously observed discrepancy between TAPSE and RV ejection fraction in the presence of regional dysfunction [54], they also analyzed RV wall motion in terms of regional stroke volume at 20 short axis slices from apex to tricuspid annulus. TAPSE assessed with CMR proved to be an unreliable measure of RV ejection fraction in patients with repaired TOF. These findings are in line with previous $3 \mathrm{D}$ echocardiographic studies which also demonstrated a weak correlation with RV ejection fraction and TAPSE [55]. The different observations made in other previous studies [42, 43] might be due to (1) the exclusion of the RV volume out of the plane in the 4-chamber view in case of 2D imaging, (2) the absence of tricuspid regurgitation, or (3) the presence of regional wall dysfunction.

In a recent study by the same group, Sheehan et al. [56] showed that the RV remodels in several directions rather than following a shape continuum. To that purpose, 15 patients with repaired TOF and 8 normal subjects by CMR in long- and short-axis views were evaluated. The RV was constructed in three dimensions using the piecewise smooth subdivision surface method. Shape was analyzed from cross-sectional contours generated by intersecting the RV with 20 planes evenly spaced from apex to tricuspid annulus. RV shape in patients with TOF differed from normal subjects in several ways. First, the RV had a larger normalized cross-sectional area in patients with TOF. Second, the cross-sectional shape was rounder in patients with TOF. In addition, the RV in patients with TOF exhibited bulging basal to the tricuspid valve which was amplified by tilting of the tricuspid annulus. Consequently, characterization of $\mathrm{RV}$ remodeling from $3 \mathrm{D}$ reconstructions provides novel insights.

In conclusion, quantitative RV shape analysis faces the same problems as volume analysis-the geometric models developed for the LV can not be applied to the RV. Neither radial nor rectangular coordinate system methods fit the RV in long or short axis views. 3D imaging methods using the multiple slice technique are more accurate because reliance on geometric modeling is eliminated. TAPSE provides useful information on RV function and shape but appears of limited use in conditions that exhibit abnormal regional contraction such as in patients with TOF. Further studies of TAPSE in conditions that alter RV anatomy, wall motion pattern, and/or tricuspid function are therefore warranted. 
Open Access This article is distributed under the terms of the Creative Commons Attribution Noncommercial License which permits any noncommercial use, distribution, and reproduction in any medium, provided the original author(s) and source are credited.

\section{References}

1. Helbing WA, Niezen RA, Le Cessie S, van der Geest RJ, Ottenkamp J, de Roos A (1996) Right ventricular diastolic function in children with pulmonary regurgitation after repair of tetralogy of Fallot: volumetric evaluation by magnetic resonance velocity mapping. J Am Coll Cardiol 28:1827-1835

2. Uebing A, Fischer G, Schmiel F, Onnasch DG, Scheewe J, Kramer HH (2005) Angiocardiographic pressure volume loops in the analysis of right ventricular function after repair of tetralogy of Fallot. Int $\mathrm{J}$ Cardiovasc Imaging 21:469-480

3. van Straten A, Vliegen HW, Hazekamp MG et al (2004) Right ventricular function after pulmonary valve replacement in patients with tetralogy of Fallot. Radiology 233:824-829

4. Gatzoulis MA, Balaji S, Webber SA et al (2000) Risk factors for arrhythmia and sudden cardiac death late after repair of tetralogy of Fallot: a multicentre study. Lancet 356:975-981

5. van den Berg J, Wielopolski PA, Meijboom FJ et al (2007) Diastolic function in repaired tetralogy of Fallot at rest and during stress: assessment with MR imaging. Radiology 243:212-219

6. Henkens IR, van Straten A, Schalij MJ et al (2007) Predicting outcome of pulmonary valve replacement in adult tetralogy of Fallot patients. Ann Thorac Surg 83:907-911

7. van Dijkman PR, Voskuil K, Hazekamp MG, van der Wall EE (1996) Imaging of recurrent ventricular septal defect and supravalvular pulmonary stenosis eight years after assumed total surgical repair of tetralogy of Fallot. Int $\mathbf{J}$ Card Imaging 12:79-83

8. Hooft van Huysduynen B, Henkens IR et al (2008) Pulmonary valve replacement in tetralogy of Fallot improves the repolarization. Int J Cardiol 124:301-306

9. Helbing WA, Roest AA, Niezen RA et al (2002) ECG predictors of ventricular arrhythmias and biventricular size and wall mass in tetralogy of Fallot with pulmonary regurgitation. Heart 88:515-519

10. Vliegen HW, van Straten A, de Roos A et al (2002) Magnetic resonance imaging to assess the hemodynamic effects of pulmonary valve replacement in adults late after repair of tetralogy of Fallot. Circulation 106:1703-1707

11. Oosterhof T, Mulder BJ, Vliegen HW, de Roos A (2006) Cardiovascular magnetic resonance in the follow-up of patients with corrected tetralogy of fallot: a review. Am Heart J 151:265-272

12. Dodge-Khatami A, Tulevski II, Bennink GB et al (2002) Comparable systemic ventricular function in healthy adults and patients with unoperated congenitally corrected transposition using MRI dobutamine stress testing. Ann Thorac Surg 73:1759-1764
13. Niezen RA, Helbing WA, van der Wall EE, van der Geest RJ, Rebergen SA, de Roos A (1996) Biventricular systolic function and mass studied with MR imaging in children with pulmonary regurgitation after repair for tetralogy of Fallot. Radiology 201:135-140

14. Oosterhof T, van Straten A, Vliegen HW et al (2007) Preoperative thresholds for pulmonary valve replacement in patients with corrected tetralogy of Fallot using cardiovascular magnetic resonance. Circulation 116:545-551

15. Oosterhof T, Jacobs M, Cramer MJ, Mulder BJ (2006) Survival into seventh decade after a potts palliation for tetralogy of Fallot. Cogenit Heart Dis 2:55-57

16. Oosterhof T, Meijboom FJ, Vliegen HW et al (2006) Longterm follow-up of homograft function after pulmonary valve replacement in patients with tetralogy of Fallot. Eur Heart J 27:1478-1484

17. Henkens IR, van Straten A, Hazekamp MG et al (2007) Preoperative determinants of recovery time in adult Fallot patients after late pulmonary valve replacement. Int $\mathbf{J}$ Cardiol 121:123-124

18. van der Velde ET, Vriend JW, Mannens MM, Uiterwaal CS, Brand R, Mulder BJ (2005) CONCOR, an initiative towards a national registry and DNA-bank of patients with congenital heart disease in the Netherlands: rationale, design, and first results. Eur J Epidemiol 20:549-557

19. Groenink M, Spijkerboer A, Mulder BJ (2005) Cardiac imaging in the digital era: how can the technicians help us further. Int J Cardiovasc Imag 21:293-294

20. Oosterhof T, Tulevski II, Roest AAW et al (2005) Disparity between dobutamine stress and physical exercise magnetic resonance imaging in patients with an intra-atrial correction for transposition of the great arteries. J Cardiovasc Magn Res 7:383-389

21. Oosterhof T, Mulder BJ, Vliegen HW, De Roos A (2005) Corrected tetralogy of Fallot: delayed enhancement in right ventricular outflow tract. Radiology 237:868-871

22. Oosterhof T, Tulevski II, Vliegen HW, Spijkerboer AM, Mulder BJ (2006) Effects of volume and/or pressure overload secondary to congenital heart disease (tetralogy of Fallot or pulmonary stenosis) on right ventricular function using cardiovascular magnetic resonance and Btype natriuretic peptide levels. Am J Cardiol 97:1051-1055

23. Oosterhof T, Vliegen HW, Meijboom FJ, Zwinderman AH, Bouma BJ, Mulder BJ (2007) Long-term effect of pulmonary valve replacement on QRS duration in patients with corrected tetralogy of Fallot. Heart 93:506-509

24. van Straten A, Vliegen HW, Lamb HJ et al (2005) Time course of diastolic and systolic function improvement after pulmonary valve replacement in adult patients with tetralogy of Fallot. J Am Coll Cardiol 46:1559-1564

25. Mulder BJ, van der Wall EE (2005) Pulmonary valve replacement in patients with tetralogy of Fallot and pulmonary regurgitation: early surgery similar to optimal timing of surgery? Eur Heart J 26:2614-2615

26. Helbing WA, Rebergen SA, Maliepaard C et al (1995) Quantification of right ventricular function with magnetic resonance imaging in children with normal hearts and with congenital heart disease. Am Heart J 130:828-837

27. Holman ER, Buller VG, de Roos A et al (1997) Detection and quantification of dysfunctional myocardium by magnetic resonance imaging. A new three-dimensional method 
for quantitative wall-thickening analysis. Circulation 95:924-931

28. van Rugge FP, Holman ER, van der Wall EE et al (1993) Quantitation of global and regional left ventricular function by cine magnetic resonance imaging during dobutamine stress in normal human subjects. Eur Heart J 14:456-463

29. van der Wall EE, van Dijkman PR, de Roos A et al (1990) Diagnostic significance of gadolinium-DTPA (diethylenetriamine penta-acetic acid) enhanced magnetic resonance imaging in thrombolytic treatment for acute myocardial infarction: its potential in assessing reperfusion. Br Heart $\mathbf{J}$ 63:12-17

30. van Dijkman PR, van der Wall EE, de Roos A et al (1991) Acute, subacute, and chronic myocardial infarction: quantitative analysis of gadolinium-enhanced MR images. Radiology 180:147-151

31. van Rugge FP, van der Wall EE, Spanjersberg SJ et al (1994) Magnetic resonance imaging during dobutamine stress for detection and localization of coronary artery disease. Quantitative wall motion analysis using a modification of the centerline method. Circulation 90:127-138

32. Bax JJ, Lamb H, Dibbets P, Pelikan H et al (2000) Comparison of gated single-photon emission computed tomography with magnetic resonance imaging for evaluation of left ventricular function in ischemic cardiomyopathy. Am J Cardiol 86:1299-1305

33. van der Wall EE, Heidendal GA, den Hollander W, Westera G, Roos JP (1980) I-123 labeled hexadecenoic acid in comparison with thallium-201 for myocardial imaging in coronary heart disease. A preliminary study. Eur J Nucl Med 5:401-405

34. Braun S, van der Wall EE, Emanuelsson S, Kobrin I (1996) Effects of a new calcium antagonist, mibefradil (Ro 405967), on silent ischemia in patients with stable chronic angina pectoris: a multicenter placebo-controlled study. The mibefradil international study group. J Am Coll Cardiol 27:317-322

35. van Lennep JE, Westerveld HT, van Lennep HW, Zwinderman AH, Erkelens DW, van der Wall EE (2000) Apolipoprotein concentrations during treatment and recurrent coronary artery disease events. Arterioscler Thromb Vasc Biol 20:2408-2413

36. Bavelaar-Croon CD, Pauwels EK, van der Wall EE (2001) Gated single-photon emission computed tomographic myocardial imaging: a new tool in clinical cardiology. Am Heart J 141:383-390

37. Molhoek SG, Bax JJ, Bleeker GB et al (2004) Comparison of response to cardiac resynchronization therapy in patients with sinus rhythm versus chronic atrial fibrillation. Am J Cardiol 94:1506-1509

38. Nijveldt R, Beek AM, Hirsch A et al (2008) 'No-reflow' after acute myocardial infarction: direct visualisation of microvascular obstruction by gadolinium-enhanced CMR. Neth Heart J 16:179-181

39. Bavelaar-Croon CD, Kayser HW, van der Wall EE et al (2000) Left ventricular function: correlation of quantitative gated SPECT and MR imaging over a wide range of values. Radiology 217:572-575

40. Buller VG, van der Geest RJ, Kool MD, van der Wall EE, de Roos A, Reiber JH (1997) Assessment of regional left ventricular wall parameters from short axis magnetic resonance imaging using a three-dimensional extension to the improved centerline method. Invest Radiol 32:529-539

41. Langerak SE, Vliegen HW, de Roos A et al (2002) Detection of vein graft disease using high-resolution magnetic resonance angiography. Circulation 105:328-333

42. Tulevski II, Lee PL, Groenink M et al (2000) Dobutamineinduced increase of right ventricular contractility without increased stroke volume in adolescent patients with transposition of the great arteries: evaluation with magnetic resonance imaging. Int J Cardiovasc Imaging 16:471-478

43. Tulevski II, Van der Wall EE, Groenink M et al (2002) Usefulness of MRI dobutamine stress in asymptomatic and minimally symptomatic patients with decreased cardiac reserve from congenital heart disease. Am J Cardiol 89:1077-1081

44. Tulevski II, Hirsch A, Dodge-Khatami A et al (2003) Effect of pulmonary valve regurgitation on right ventricular function in patients with chronic right ventricular pressure overload. Am J Cardiol 92:113-116

45. Tulevski II, Zijta FM, Smeijers AS et al (2004) Regional and global right ventricular dysfunction in asymptomatic or minimally symptomatic patients with congenitally corrected transposition of the great arteries. Cardiol Young 14:168-173

46. Van der Zedde J, Oosterhof T, Tulevski II, Vliegen HW, Mulder BJ (2005) Comparison of segmental and global systemic ventricular function at rest and during dobutamine stress between patients with transposition and congenitally corrected transposition. Cardiol Young 15:148-153

47. Tulevski II, Dodge-Khatami A, Groenink M, Van der Wall EE, Romkes H, Mulder BJ (2003) Right ventricular function in congenital cardiac disease: noninvasive quantitative parameters for clinical follow-up. Cardiol Young 13:397403

48. Kayser HW, Stoel BC, van der Wall EE, van der Geest RJ, de Roos A (1997) MR velocity mapping of tricuspid flow: correction for through-plane motion. J Magn Reson Imaging 7:669-673

49. Greenberg SB, Shah CC, Bhutta ST (2008) Tricuspid valve magnetic resonance imaging phase contrast velocityencoded flow quantification for follow up of tetralogy of Fallot. Int J Cardiovasc Imaging 24:861-865

50. Tamborini G, Pepi M, Galli CA et al (2007) Feasibility and accuracy of a routine echocardiographic assessment of right ventricular function. Int J Cardiol 115:86-89

51. Ghio S, Recusani F, Klersy C et al (2000) Prognostic usefulness of the tricuspid annular plane systolic excursion in patients with congestive heart failure secondary to idiopathic or ischemic dilated cardiomyopathy. Am J Cardiol 85:837-842

52. Forfia PR, Fisher MR, Mathai SC et al (2006) Tricuspid annular displacement predicts survival in pulmonary hypertension. Am J Respir Crit Care Med 174:1034-1041

53. Morcos P, Vick GW, Sahn D, Jerosh-Herald M, Shurman A, Sheehan FH (2008) Correlation of right ventricular ejection fraction and tricuspid annular plane systolic excursion in tetralogy of fallot by magnetic resonance imaging. Int J Cardiovasc Imaging [Epub ahead of print] 
54. Smith JL, Bolson EL, Wong SP, Hubka M, Sheehan FH (2003) Three-dimensional assessment of two-dimensional technique for evaluation of right ventricular function by tricuspid annulus motion. Int $\mathrm{J}$ Cardiovasc Imaging 19:189-197

55. Kjaergaard J, Petersen CL, Kjaer A, Schaadt BK, Oh JK, Hassager C (2006) Evaluation of right ventricular volume and function by 2D and 3D echocardiography compared to MRI. Eur J Echocardiogr 72:430-438

56. Sheehan FH, Ge S, Vick GW et al (2008) Three-dimensional shape analysis of right ventricular remodeling in repaired tetralogy of Fallot. Am J Cardiol 101:107-113 